\section{Undergraduate Research in the Twenty-First Century}

\author{
doi: $10.18833 /$ spur/3/3/8
}

W ith the benefits of undergraduate research well-documented and widely acknowledged as fostering institutional engagement as well as educational gains, SPUR looks ahead to new developments in undergraduate research for the twenty-first century. In this themed issue, authors explore the practice of undergraduate research in a variety of institutional contexts: public and private universities, equity-oriented institutions, liberal arts colleges - reflecting the diversity and the financial realities of the higher education landscape. The authors share creative approaches-both focused and wide-ranging - to integrate undergraduate research more widely into the curriculum and institutional culture, with a focus on the relevance of these experiences for the workplace. Equity, access, engagement, and empowerment are at the heart of this issue as authors explore how undergraduate research serves a vital role in fostering student learning and success across diverse institutions.

Several practice articles in this issue explore structural efforts within and across campuses to expand student access and amplify the impacts of undergraduate research. Patrick Corbett and Jody R. Rosen share the transformational work they have accomplished at the New York City College of Technology-CUNY, an opportunity-granting institution, to increase participation in inquiry-driven learning experiences across the curriculum. They developed an "expanded ecosystem of undergraduate research" by infusing research experiences across the curriculum; supporting a cohort-model of professional development for faculty; and designing a digital space for teaching, learning, and collaboration. Prajukti Bhattacharyya and colleagues discuss an initiative at the University of Wisconsin-Whitewater's two- and four-year campuses to make undergraduate research more broadly accessible through course-based research experiences in multiple disciplines. The Research across Curriculum (RAC) project created a community of practice for faculty working through the challenges associated with developing and teaching research-infused courses. The article includes detailed examples from courses in geography, political science, chemistry, and mathematics, including learning outcomes and project descriptions, as well as a discussion of the challenges involved in developing and teaching research-infused courses.
Kimberly J. McClure-Brenchley and colleagues discuss efforts at St. John Fisher College to expand engagement with undergraduate research within academic departments and launch synergistic partnerships between academic departments and the career center. Undergraduate research experiences become a bridge between the knowledge and skills developed within a discipline and actively connecting those to different career directions. In this highly collaborative partnership, faculty and staff work together to support student access to research opportunities on and off campus and to help students within the major articulate the ways in which their educational experience leads to relevant skills and competencies in demand by employers.

Shifting the focus to the power of student-initiated endeavors, Alison Rios Millett McCartney and colleagues describe their success at Towson University in establishing an undergraduate research club. They also offer practical advice for other campuses seeking to initiate more formal support for undergraduate research on a campus with limited financial resources. It's a creative and innovative approach that highlights how effective student, faculty, and administrative partnerships can be. At Towson, it has enabled students to build a community of undergraduate researchers on campus and generate financial support for presenting their work at conferences.

This themed issue concludes with four vignettes exploring ways of expanding access to undergraduate research and fostering a community among researchers. Monica Berger shares the impact of opening up her institution's digital repository to student presentations and papers. For students, this allows for greater dissemination of their work to employers and graduate schools as well as a space to see themselves as part of a community of researchers. Cord M. Brundage describes the numerous benefits of undergraduate research clubs, such as the one focused on veterinary sciences at his campus. By organizing in a club format, students not only gain access to funding to support conference participation - a benefit also noted by McCartney - but they have a vital community forum for sharing specialized research training, practicing presentations, promoting peer mentorship, and increasing support of peer research projects. In the classroom, Kevin J. Holmes details his use of real-world "hot-button" issues as a way of engaging students in basic research and scaffolding those efforts to help students develop from introductory research efforts to more sophisticated work on research questions that lead to presentations and potentially scholarly publications. Nicholas J. Rowland and Matthew J. Spaniol discuss scenario planning as 
a newly recognized form of undergraduate research. A practice adapted from military intelligence, scenario planning engages students in identifying root causes of a situation and mapping out consequences of various courses of action. This practice, the authors note, contributes to a "futures literacy"- the ability to understand how the present shapes the future - and is directly applicable to current and evolving workplace needs.

These initiatives illustrate how campuses are effectively reshaping the undergraduate research landscape by focusing efforts in multiple areas: classrooms, libraries, administrative offices, and student organizations. Although undergraduate research remains an evidence-based, highimpact practice that is still largely elective on campuses (Hart Research Associates, 2015), this issue details how institutions can expand access; generate a more robust culture of research on campus; and provide research experiences through undergraduate research experiences, coursebased undergraduate research experiences, internships, and research infusions into courses at multiple levels to foster the inquiry-based learning and skill development highly valued by employers as well as graduate schools (Hart Research Associates, 2018).

\section{References}

Kuh, George D. 2008. High-Impact Educational Practices: What They Are, Who Has Access to Them, and Why They Matter. Washington, DC: Association of American Colleges and Universities.

Hart Research Associates. 2015. Bringing Equity and Quality Learning Together: Institutional Priorities for Tracking and Advancing Underserved Students' Success Key Findings from a Survey and In-Depth Interviews among Administrators at $A A C \& U$ Member Institutions. Washington, DC: Association of American Colleges and Universities.

Hart Research Associates. 2018. Fulfilling the American Dream: Liberal Education and the Future of Work. Selected Findings from Online Surveys of Business Executives and Hiring Managers. Washington, DC: Association of American Colleges and Universities.

\section{Looking for a past SPUR or CUR Quarterly article? Visit CUR's online article search: https://bit.ly/SPUR-CURQSearch}

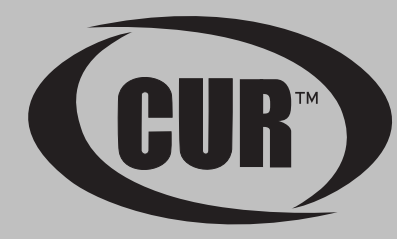

